PRECISION AND BIAS OF SELECTED ANALYTES REPORTED BY THE

NATIONAL ATMOSPHERIC DEPOSITION PROGRAM AND

NATIONAL TRENDS NETWORK--1983 AND

JANUARY 1980 THROUGH SEPTEMBER 1984

By LeRoy J. Schroder and Amy W. Bricker, U.S. Geological Survey and Timothy C. Willoughby, Goodson and Associates

U.S. GEOLOGICAL SURVEY

Water-Resources Investigations Report 85-4275

Lakewood, Colorado

1985 


\section{UNITED STATES DEPARTMENT OF THE INTERIOR}

DONALD PAUL HODEL, Secretary

GEOLOGICAL SURVEY

Dallas L. Peck, Director

\begin{tabular}{ll}
\hline $\begin{array}{l}\text { For additional information } \\
\text { write to: }\end{array}$ & $\begin{array}{c}\text { Copies of this report can be } \\
\text { purchased from: }\end{array}$ \\
LeRoy J. Schroder & Open-File Services Section \\
U.S. Geological Survey & Western Distribution Branch \\
Box 25046, Mail Stop 407 & U.S. Geological Survey, MS 306 \\
Denver Federal Center & Box 24525, Denver Federal Center \\
Lakewood, Colorado 80225 & Denver, CO 80225 \\
& Telephone (303) 236-7476
\end{tabular}


Abstract--

Introduction--1 1

Preparation and analysis of performance-audit samples-1-0.-- 2

Precision and bias of selected analytes-1 3

Results for 1983-........ 3

Results for January 1980 through September 1984-_.-. 6

Comparison of results for the two periods-1 13

Summary--

References cited--_- 15

\section{ILLUSTRATIONS}

Figures 1-6. Graphs showing degree of bias based on:

1. Known calcium concentration in performance-audit samples for 1983-..- 7

2. Known magnesium concentration in performance-audit samples for 1983-.-1 7

3. Known sodium concentration in performance-audit samples for 1983-.-.- 8

4. Known potassium concentration in performance-audit samples for 1983-1 9

5. Known sulfate concentration in performance-audit samples for 1983--10

6. Known chloride concentration in performance-audit samples for 1983-_.- 10

TABLES

Table 1. Concentrations of analytes (5th, 50th, and 95th percentiles) in precipitation samples collected for the National Atmospheric Deposition Program and National Trends Network during 1983-.-.

2. Performance-audit sample concentration range for the National Atmospheric Deposition Program and National Trends Network during 1983-.-.--

3. Relative-percent difference between the National Atmospheric Deposition Program and National Trends Network reported analyte concentrations and known performance-audit-sample concentrations for 1983----10-

4. Bias determination from comparing the National Atmospheric Deposition Program and National Trends

Network reported analyte concentrations and the known performance-audit-sample concentrations for 1983------

5. Estimated pooled standard deviation and 95-percent confidence limits of the National Atmospheric Deposition Program and National Trends Network reported analyte concentrations for 1983-- 
Table 6. Median relative-percent difference between the National

Page Atmospheric Deposition Program and National Trends Network reported analyte concentrations and the known performance-audit-sample concentrations for January 1980 through September 1984-12

7. Bias determination from comparing the National Atmospheric Deposition Program and National Trends Network reported analyte concentrations and the known performance-audit-sample concentrations for January 1980 through September 1984-12

8. Estimated variance of the National Atmospheric Deposition Program and National Trends Network reported analyte concentrations for 1983

9. Estimated variance of the National Atmospheric Deposition
Program and National Trends Network reported analyte concentrations for January 1980 through September 1984------

\section{METRIC CONVERSION TABLE}

For the reader who may prefer to use inch-pound units, conversion factors for terms used in this report are listed below:

Multiply SI units

milliliter (mL)

micrometer $(\mu \mathrm{m})$

$$
\text { By }
$$

.03382

$3.937 \times 10^{-5}$
To obtain inch-pound units

ounce, fluid

inch 


\title{
PRECISION AND BIAS OF SELECTED ANALYTES REPORTED BY THE NATIONAL ATMOSPHERIC DEPOSITION PROGRAM AND NATIONAL TRENDS NETWORK--1983 AND JANUARY 1980 THROUGH SEPTEMBER 1984
}

\author{
By LeRoy J. Schroder and Amy W. Bricker, \\ U.S. Geological Survey, Lakewood, Colorado \\ and Timothy $\mathrm{C}$. Willoughby, \\ Goodson and Associates, Lakewood, Colorado
}

\begin{abstract}
Performance-audit samples with known analyte concentrations have been prepared by the U.S. Geological Survey and distributed to the National Atmospheric Deposition Program's Central Analytical Laboratory. The difference between the National Atmospheric Deposition Program and National Trends Network reported analyte concentrations and known analyte concentrations have been calculated, and the bias has been determined. For 1983, concentrations of calcium, magnesium, sodium, and chloride were biased at the 99-percent confidence limit; concentrations of potassium and sulfate were unbiased at the 99-percent confidence limit. Relative-percent differences between the measured and known analyte concentration for calcium, magnesium, sodium, potassium, chloride, and sulfate have been calculated for 1983 . The median relative-percent difference for calcium was 17.0 ; magnesium was 6.4 ; sodium was 10.8 ; potassium was 6.4 ; chloride was 17.2 ; and sulfate was -5.3 . These relative percent differences need to be considered before user-analysis of the 1983 data.
\end{abstract}

Variances have been calculated for calcium, magnesium, sodium, potassium, chloride, and sulfate determinations. These variances should be applicable to the natural-sample analyte concentrations reported by the National Atmospheric Deposition Program and National Trends Network for 1983.

\section{INTRODUCTION}

The National Atmospheric Deposition Program (NADP) was organized in 1977 by a number of State agricultural experiment stations to provide information on the spatial.and temporal trends of atmospheric deposition in the United States. Extensive participation was obtained from other organizations because of the broad interest in the subject. The National Trends Network (NTN) was established by the Deposition Monitoring Task Group of the Interagency Task Force on Acid Precipitation in 1983. Sampling sites may be part of either one or both of the monitoring networks. Therefore, this report will consider the NADP and NTN as one group known as NADP/NTN. Operators of individual sampling sites use standardized instrumentation and procedures to collect weekly wet-deposition samples. These samples are sent to the Central Analytical Laboratory (CAL) at the Illinois State Water Survey where all samples are analyzed for ammonium, calcium, magnesium, sodium, potassium, chloride, 
sulfate, nitrate, and phosphate. These analyses are reported to the NADP/NTN Coordinator's Office which publishes the data and submits the data for computerized storage by Pacific Northwest Laboratory for the U.S. Environmental Protection Agency.

As part of its contribution to the NADP/NTN, a performance-audit program has operated for nearly 4 years by the U.S. Geological Survey in Denver, Colorado, in cooperation with sampling-site operators and CAL personnel. This program relies on the sampling-site operators to submit performance-audit samples to CAL after a week in which no wet deposition has occurred at their site. Site operators attempt to camouflage or disguise the performance-audit sample by submitting fictitious collection data with the sample. The goal of the performance-audit program is to have 1 sample submitted to CAL about once each week by 1 of the sampling-site operators; the actual number of samples submitted from the sites to CAL has averaged about 1 sample every 2 weeks.

This report: (1) Describes the NADP/NTN performance-audit program managed by the U.S. Geological Survey; (2) presents the absolute and relative percent differences between the NADP/NTN reported analyte concentrations and the performance-sample concentrations; and (3) presents the precision of the NADP/NTN reported concentrations, using the estimated variance. The report documents the results of the program for 1983 and for January 1980 through September 1984.

\section{PREPARATION AND ANALYSIS OF PERFORMANCE-AUDIT SAMPLES}

Performance-audit samples are prepared by the U.S. Geological Survey in Denver, Colorado. The samples are prepared by diluting standard reference water samples (Schroder and others, 1980; Skougstad and Fishman, 1974) with deionized water. A sample volume of 2,000 milliliters is prepared for each mixture and divided into 500 milliliter aliquots; then the $\mathrm{pH}$ of each solution is lowered to less than 5.0, using perchloric acid. The performance-audit samples are sent directly to NADP/NTN site operators on a quarterly basis. After a week in which no wet deposition has occurred, site operators take a 20 milliliter aliquot from the sample and determine the $\mathrm{pH}$ and specific conductivity of the sample. A portion (about 80 percent) of the remaining sample is poured into a pre-cleaned polyethylene sample container; then the container is sealed and shipped to CAL without prior notification. CAL filters all precipitation samples, using 0.45-micrometer pore-size filters, before analysis. All CAL analytical data are transmitted to the U.S. Geological Survey at Denver, Colorado; this laboratory identifies the performance-auditsample data and notifies CAL that the data are to be removed from their data files. The diluted standard reference water samples do not contain ammonia at a detectable concentration; nitrate and phosphate are lost from the samples after dilution by the U.S. Geological Survey and before analysis by CAL. 
CAL reanalyzes all performance-audit samples after the samples are identified by the U.S. Geological Survey. These samples normally are stored for 3 to 4 months at room temperature before the second analysis occurs. These data are transmitted to the U.S. Geological Survey after analysis. CAL may analyze each performance-audit sample a total of 8 times: 4 analyses of the individual 500-milliliter aliquots sent to CAL from sampling-site operators, and 4 reanalyses of aliquots. CAL has analyzed individual performance-audit samples an average of 5 times from January 1980 through September 1984.

\section{PRECISION AND BIAS OF SELECTED ANALYTES}

Performance-audit samples are handled by the site operator, transported to the laboratory in a polyethylene sampling bucket, and filtered at the laboratory. This series of steps is nearly identical to the handling that a natural precipitation sample receives. The analyte concentrations for calcium, magnesium, sodium, potassium, chloride, and sulfate reported to the U.S. Geological Survey probably are affected by the sample handling process prior to the laboratory determination. Therefore, the data obtained from the performance-audit sample are considered to be a monitor for the entire NADP/NTN sample handling, transportation, and analysis routine.

\section{Results for 1983}

The 1983 natural precipitation samples collected by the NADP/NTN have relatively low analyte concentrations. A summary of these analyte-percentile concentrations is presented in table 1 . The concentration range of analytes in the 1983 performance-audit samples is summarized in table 2. Comparison of the data from tables 1 and 2 indicates that the performance-audit-sample analyte concentrations for several analytes are usually greater than the 50th percentile natural-sample analyte concentrations. This was necessary to produce stable analyte concentrations in the performance-audit samples. 
Table 1.--Concentrations of analytes (5th, 50th, and 95th percentiles) in precipitation samples collected for the National Atmospheric Deposition Program and

National Trends Network during 1983.

[Mark Peden, Illinois State Water Survey, written commun., 1985; $\mathrm{mg} / \mathrm{L}$, milligrams per liter]

\begin{tabular}{lccc}
\hline & \multicolumn{3}{c}{ Percentile } \\
\cline { 2 - 4 } \multicolumn{1}{c}{ Analyte } & $\begin{array}{c}5 \mathrm{th} \\
(\mathrm{mg} / \mathrm{L})\end{array}$ & $\begin{array}{c}50 \mathrm{th} \\
(\mathrm{mg} / \mathrm{L})\end{array}$ & $\begin{array}{c}95 \mathrm{th} \\
(\mathrm{mg} / \mathrm{L})\end{array}$ \\
\hline Calcium & 0.027 & 0.160 & 1.51 \\
Magnesium & .010 & .040 & .259 \\
Sodium & .022 & .102 & 1.089 \\
Potassium & .007 & .031 & .192 \\
Sulfate & .32 & 1.38 & 5.92 \\
Chloride & .05 & .17 & 1.73 \\
\hline
\end{tabular}

Table 2.--Performance-audit-sample concentration range for the National Atmospheric Deposition Program and National Trends Network during 1983.

\begin{tabular}{lccc}
\hline \multicolumn{1}{c}{ Analyte } & $\begin{array}{c}\text { Concentration range } \\
\text { (milligrams }\end{array}$ & Ner liter) & Number of samples \\
\hline Calcium & $0.30-7.24$ & 28 \\
Magnesium & $.08-1.54$ & 28 \\
Sodium & $.24-7.43$ & 28 \\
Potassium & $.06-1.87$ & 28 \\
Sulfate & $.58-14.40$ & 28 \\
Chloride & $.056-3.87$ & \\
\end{tabular}


Analyte concentrations obtained from the CAL analyses of the performanceaudit samples are compared to the most-probable values or known analyte concentrations by the U.S. Geological Survey at Denver, Colorado. The relative-percent difference between CAL-reported analyte concentrations and the known performance-audit-sample concentrations were calculated by:

$$
\frac{\text { CAL reported concentration - known concentration }}{\text { Known concentration }} \times 100 \text {. }
$$

The relative-percent differences for the 1983 performance-audit samples are summarized in table 3 . The median and mean relative-percent differences are positive for each analyte except sulfate. The median relative-percent difference probably is a better description of the bias than the mean for this data set because of the range of data. For example, relative-percent differences for calcium ranged from -2.07 to 69.4 percent.

Table 3.--Relative-percent difference between the National Atmospheric Deposition Program and National Trends Network reported analyte concentrations and the known performance-audit-sample concentrations for 1983.

\begin{tabular}{lrrrr}
\hline \multirow{2}{*}{ Analyte } & \multicolumn{2}{c}{ Relative percent difference } & Number of \\
\cline { 2 - 4 } & Median & Mean & $\begin{array}{r}\text { Standard } \\
\text { deviation }\end{array}$ & \\
\hline Samples & & \\
Calcium & 17.0 & 20.4 & 18.2 & 28 \\
Magnesium & 6.4 & 14.3 & 21.2 & 28 \\
Sodium & 10.8 & 17.3 & 19.3 & 28 \\
Potassium & 6.4 & 14.3 & 21.2 & 28 \\
Sulfate & -5.3 & -2.8 & 11.9 & 28 \\
Chloride & 17.2 & 27.2 & 28.4 & 28 \\
& & & & \\
\hline
\end{tabular}


Bias for the analyte concentrations is determined by comparing the CAL-reported analyte concentrations to the known audit-sample concentrations. These comparisons are shown in figures 1 through 6. Peart and Thomas (1983) and Grant and Leavenworth (1974) present a binomial-probability-distribution equation in which the probability of having $X$ or more points on the same side of zero can be calculated. If $X$ or more points occur on the same side of zero, bias is assumed. Bias was tested at 1-percent probability and summarized on table 4. Reported concentrations of calcium, magnesium, sodium, and chloride were determined to be biased for 1983.

A paired t-test (Dixon and Massey, 1969) was used to test the hypothesis that the initial NADP reported results were equal to reanalysis results for 1983. This hypothesis is accepted for the analytes calcium, magnesium, sodium, potassium, sulfate, and chloride.

Least-squares equations were calculated to determine if a significant regression occurred between the standard deviation of the performance-audit samples and the analyte concentrations in these same samples. It was determined that the standard deviation is not significantly dependent on the analyte concentration (Dixon and Massey, 1969).

Pooled standard deviations for 1983 performance-audit samples are presented in table 5. If these pooled standard deviations are applied to analyte concentrations beyond the concentration limits tested, caution is suggested.

\section{Results for January 1980 through September 1984}

Performance-audit-sample data for January 1980 through September 1984 are summarized in tables 6 and 7 . Median relative percent differences are given because the median appears to give a better description of the bias than the mean. For example, relative-percent differences for calcium ranged from -6.5 percent to 263 percent. Reported concentrations for calcium, magnesium, sodium, sulfate, and chloride were determined to be biased, as summarized in table 7 . 


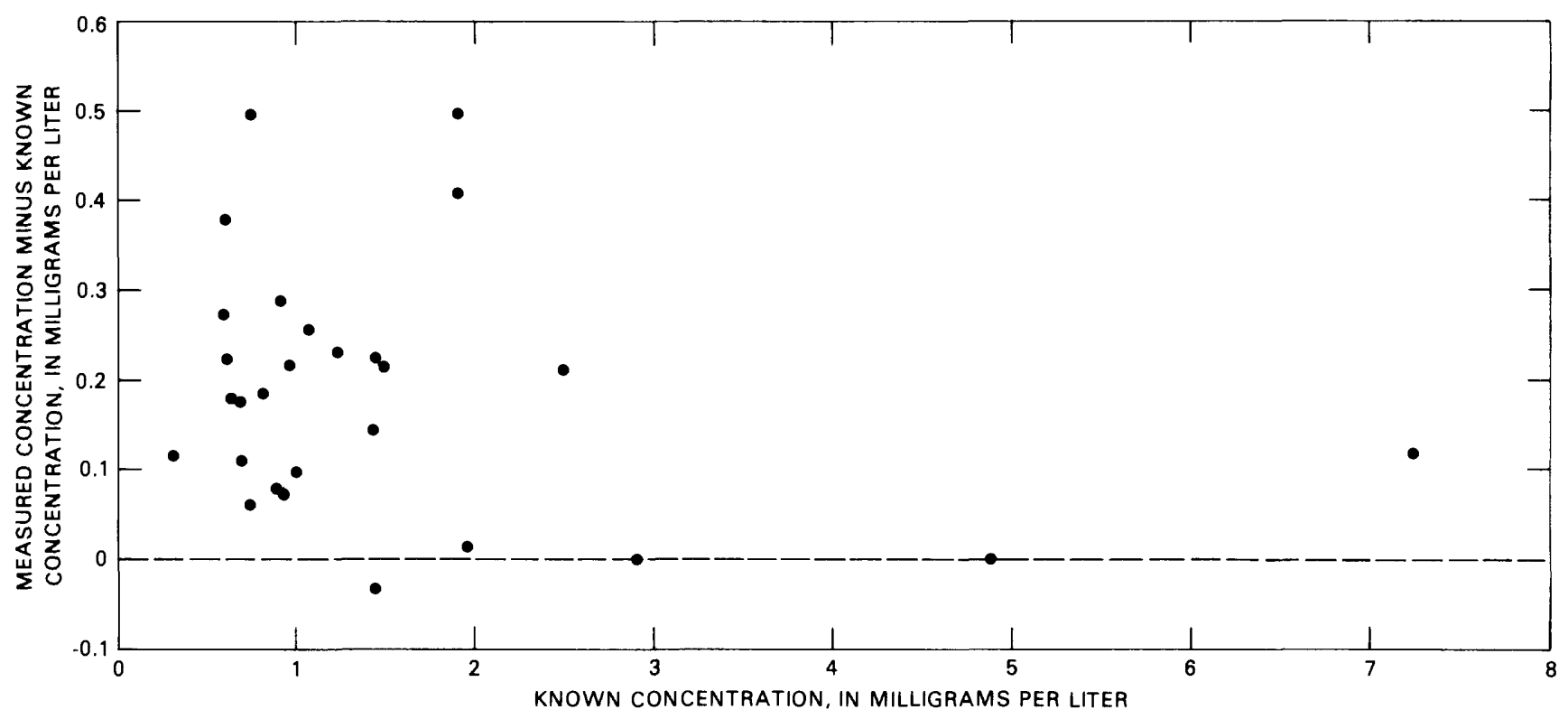

Figure 1.--Degree of bias based on known calcium concentration in performance-audit samples for 1983 .

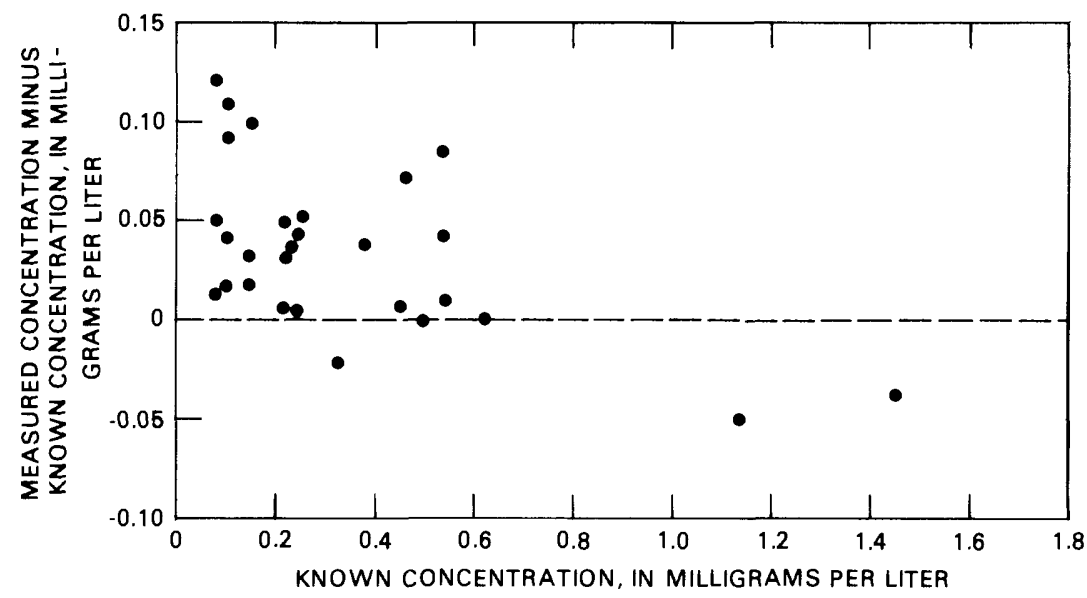

Figure 2.--Degree of bias based on known magnesium concentration in performance-audit samples for 1983 . 


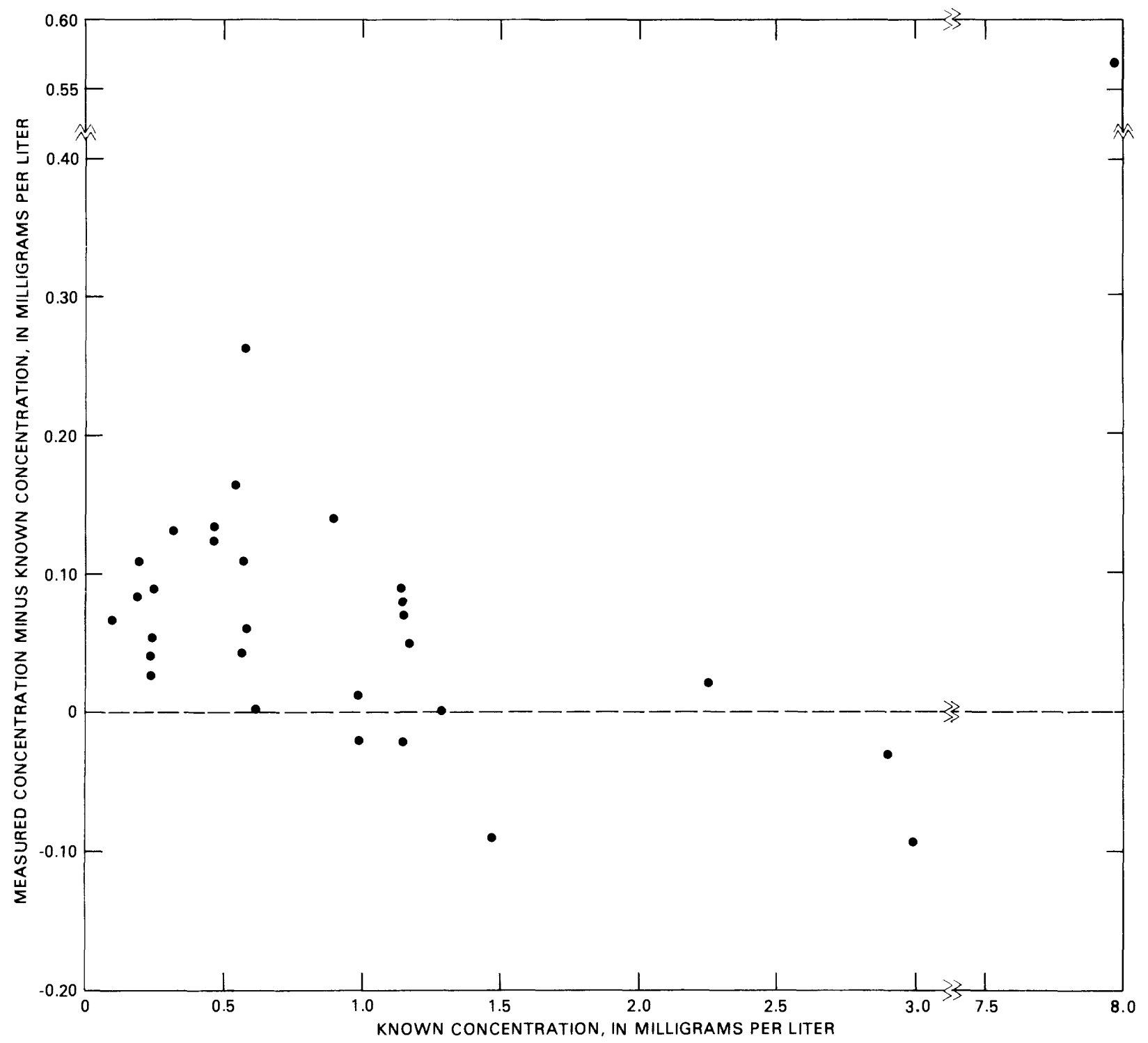

Figure 3.--Degree of bias based on known sodium concentration in performance-audit samples for 1983 . 


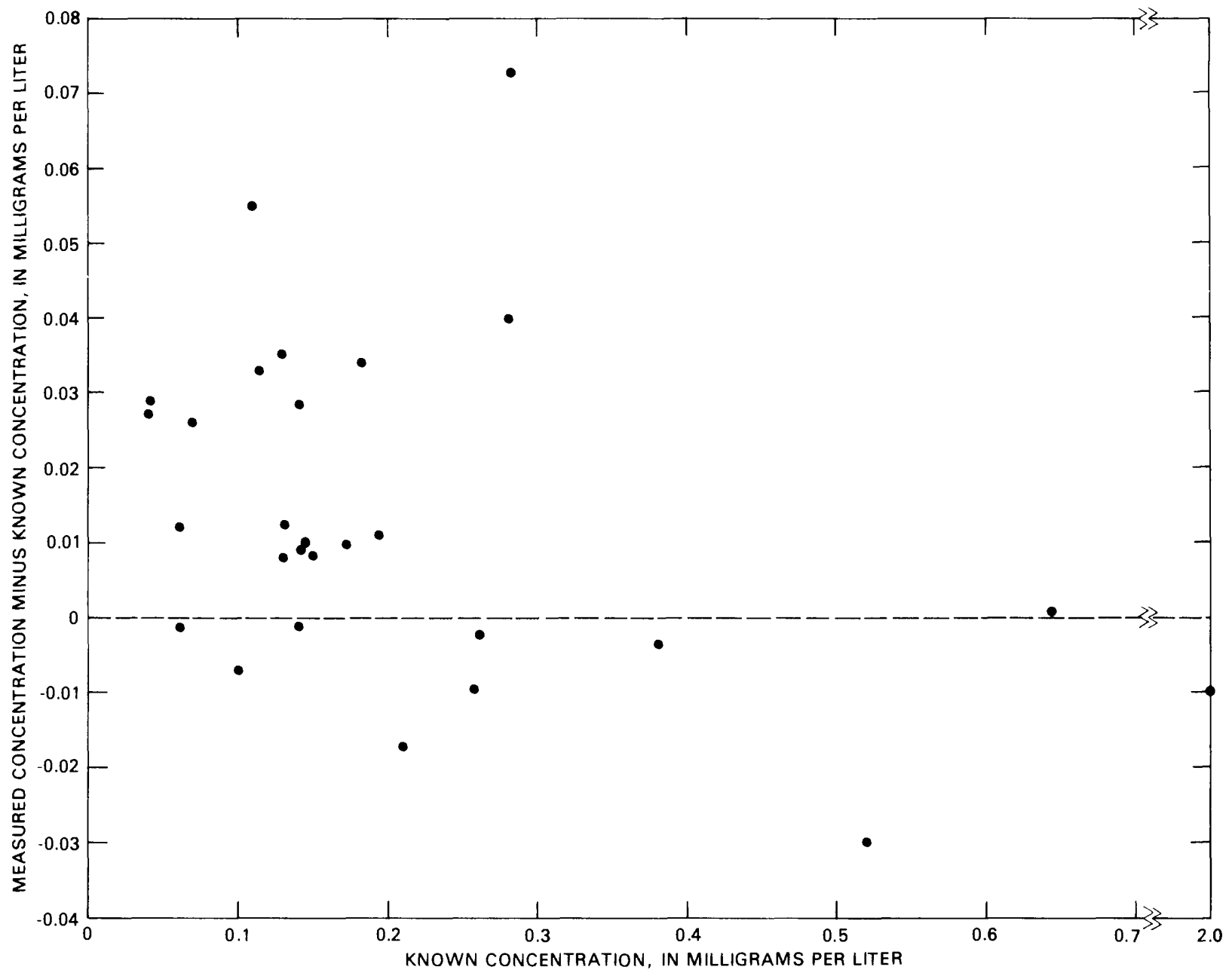

Figure 4.--Degree of bias based on known potassium concentration in performance-audit samples for 1983. 


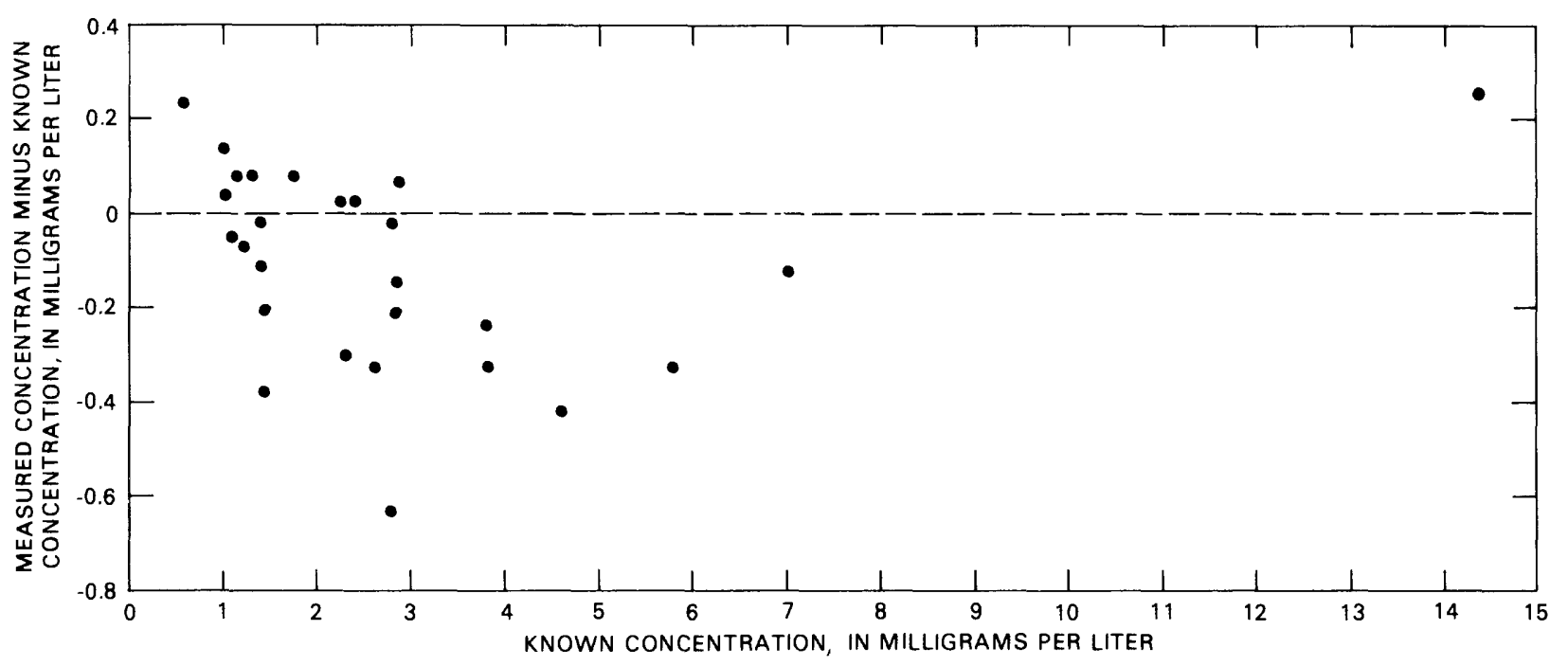

Figure 5.--Degree of bias based on known sulfate concentration in performance-audit samples for 1983.

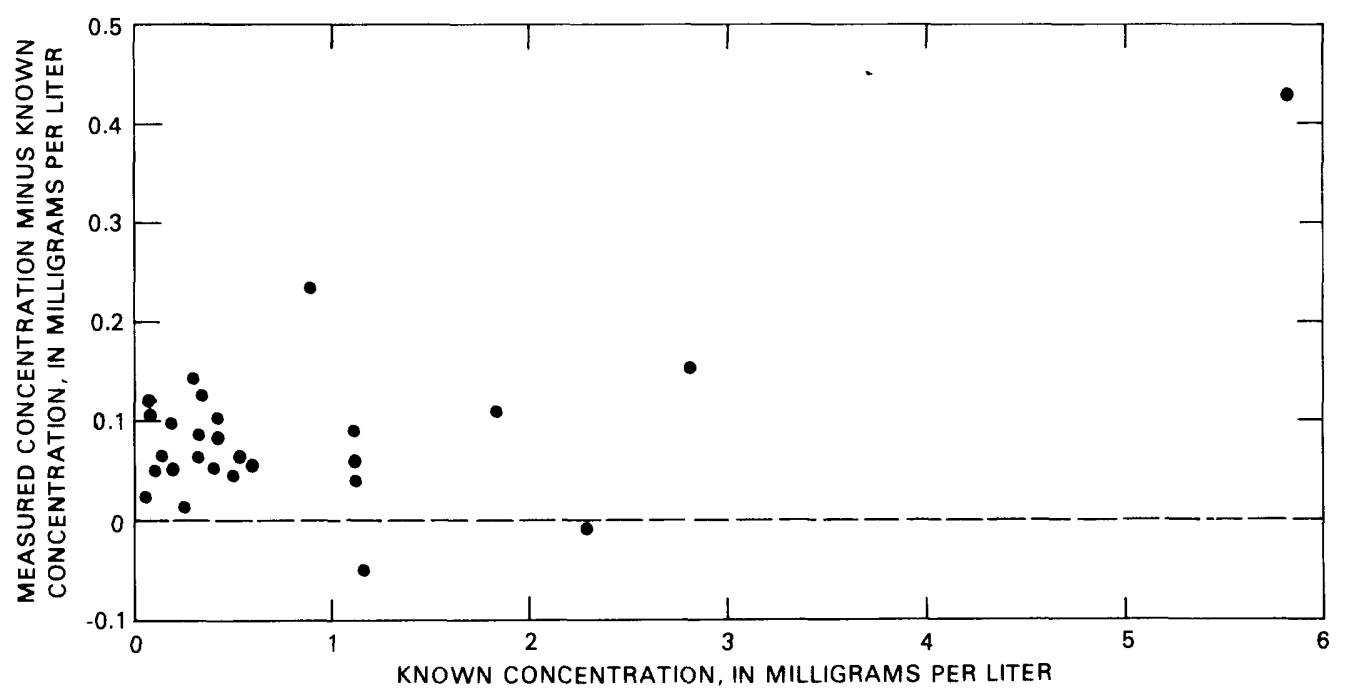

Figure 6.--Degree of bias based on known chloride concentration in performance-audit samples for 1983 . 
Table 4.--Bias determination from comparing the National Atmospheric Deposition Program and National Trends Network reported analyte concentrations and the known performance-audit-sample concentrations for 1983 .

\begin{tabular}{lccl}
\hline \multicolumn{1}{c}{ Analyte } & $\begin{array}{c}\text { Maximum number of } \\
\text { values on the same } \\
\text { side of zero }\end{array}$ & $\begin{array}{c}\text { Number of } \\
\text { samples }\end{array}$ & Bias \\
\hline Calcium & 25 & 28 & Positive \\
Magnesium & 23 & 28 & Positive \\
Sodium & 22 & 28 & Positive \\
Potassium & 19 & 28 & None \\
Sulfate & 17 & 28 & None \\
Chloride & 26 & 28 & Positive \\
& & & \\
\hline
\end{tabular}

Table 5.--Estimated pooled standard deviation and 95 percent confidence limits of the National Atmospheric Deposition Program and National Trends Network reported analytes for 1983.

[mg/L, milligrams per liter]

\begin{tabular}{|c|c|c|c|c|c|c|}
\hline \multirow{2}{*}{$\frac{\text { Analyte }}{\text { Calcium }}$} & \multicolumn{2}{|c|}{$\begin{array}{l}\text { Concentration } \\
\text { range } \\
(\mathrm{mg} / \mathrm{L})\end{array}$} & \multirow{2}{*}{$\begin{array}{c}\begin{array}{c}\text { Pooled } \\
\text { standard } \\
\text { deviation } \\
(\mathrm{mg} / \mathrm{L})\end{array} \\
0.08\end{array}$} & \multicolumn{3}{|c|}{$\begin{array}{c}\text { 95-percent } \\
\text { confidence limits } \\
\text { of pooled standard } \\
\text { deviation } \\
(\mathrm{mg} / \mathrm{L})\end{array}$} \\
\hline & 0.30 & 7.24 & & 0.07 & - & 0.10 \\
\hline Magnesium & .080 & 1.54 & .03 & .03 & - & .04 \\
\hline Sodium & .24 & 7.43 & .05 & .04 & - & .06 \\
\hline Potassium & .060 & 1.87 & .01 & .01 & - & .01 \\
\hline Sulfate & .58 & -14.40 & .13 & .11 & - & .16 \\
\hline Chloride & .056 & $-\quad 3.87$ & .04 & .03 & - & .05 \\
\hline
\end{tabular}


Table 6.--Median relative-percent difference between the National Atmospheric Deposition Program and National Trends Network reported analyte concentrations and the known performance-audit-sample concentrations for January 1980 through September 1984.

\begin{tabular}{lcc}
\hline Analyte & $\begin{array}{c}\text { Mean relative percent } \\
\text { difference }\end{array}$ & $\begin{array}{c}\text { Number of } \\
\text { samples }\end{array}$ \\
\hline Calcium & 6.08 & 135 \\
Magnesium & 6.42 & 135 \\
Sodium & 5.21 & 133 \\
Potassium & 1.00 & 135 \\
Sulfate & 3.05 & 133 \\
Chloride & 10.9 & 133 \\
\hline
\end{tabular}

Table 7.--Bias determination from comparing the National Atmospheric Deposition Program and National Trends Network reported analyte concentrations and the known performance-audit-sample concentrations for January 1980 through September 1984.

\begin{tabular}{lccl}
\hline \multicolumn{1}{c}{$\begin{array}{c}\text { Maximum } \\
\text { Analyte }\end{array}$} & $\begin{array}{c}\text { on } \\
\text { on ther same side } \\
\text { of zero }\end{array}$ & $\begin{array}{c}\text { Number of } \\
\text { samples }\end{array}$ & Bias \\
\hline Calcium & 107 & 135 & Positive \\
Magnesium & 100 & 135 & Positive \\
Sodium & 94 & 133 & Positive \\
Potassium & 73 & 135 & None \\
Sulfate & 90 & 133 & Positive \\
Chloride & 105 & 133 & Positive \\
& & & \\
\hline
\end{tabular}




\section{Comparison of Results for the Two Periods}

Analyses of performance-audit samples have been used to estimate the variances of the NADP/NTN-reported analyte concentrations. Variances for calcium, magnesium, sodium, potassium, sulfate, and chloride are given in tables 8 and 9 . The variances for each analyte are estimated using a pooling or averaging technique from Dixon and Massey (1969) and Walpole and Myers (1972). The formula used for this estimate is:

$$
s_{p}{ }^{2}=\frac{\left(n_{1}-1\right) s_{1}{ }^{2}+\left(n_{2}-1\right) s_{2}^{2}+\cdot \cdot++\left(n_{k}-1\right) s_{k}{ }^{2}}{n_{1}+n_{2}+\cdot \cdot+n_{k}-k}
$$

where

$$
\begin{aligned}
& s_{p}^{2}=\text { the unbiased estimate of the variance } \sigma^{2} \text { for each analyte; } \\
& n=\text { the number of times each performance-audit sample was } \\
& \text { analyzed; } \\
& s^{2}=\text { the variance for each particular performance-audit sample; } \\
& \text { and } \\
& k=\text { the number of different performance-audit samples used in } \\
& \text { the population. }
\end{aligned}
$$

Only performance-audit samples that were analyzed three or more times were used to calculate the variance for each analyte. These estimated variances should be valid for natural samples with analytes in the concentration ranges shown in tables 8 and 9 . Caution needs to be used if the variances are applied to analyte concentrations beyond the limits of the concentrations tested, because the variances may not be applicable.

Table 8.--Estimated variance of the National Atmospheric Deposition Program and National Trends Network reported analyte concentrations for 1983 .

\begin{tabular}{lccc} 
Analyte & (milligrams per liter) & Estimated va \\
\hline Calcium & $0.30-7.24$ & 0.006 \\
Magnesium & $.080-1.54$ & .001 \\
Sodium & $.24-7.43$ & .003 \\
Potassium & $.060-1.87$ & .0002 \\
Sulfate & $.58-14.40$ & .018 \\
Chloride & $.056-3.87$ & .002
\end{tabular}


Table 9.--Estimated variance of the National Atmospheric Deposition Program and National Trends Network reported analyte concentrations

for January 1980 through September 1984.

\begin{tabular}{lrr}
\hline \multicolumn{1}{c}{ Analyte } & $\begin{array}{c}\text { Concentration range } \\
\text { (milligrams per liter) }\end{array}$ & Estimated variance \\
\hline Calcium & $0.30-7.48$ & 0.023 \\
Magnesium & $.04-04-58$ & .006 \\
Sodium & $.11-7.43$ & .015 \\
Potassium & $.04-1.87$ & .058 \\
Sulfate & $.58-15.52$ & .012 \\
Chloride & $.06-5.80$ & \\
\hline
\end{tabular}

\section{SUMMARY}

Performance-audit samples were used to determine the possible bias of the concentrations of calcium, magnesium, sodium, potassium, sulfate, and chloride reported by NADP/NTN for 1983 and for January 1980 through September 1984. Bias was tested at 1-percent probability. Calcium, magnesium, sodium, and chloride concentrations were determined to be biased for both time periods. Sulfate results were determined to be unbiased for 1983 but biased for January 1980 through September 1984. Potassium results were determined to be unbiased for both time periods.

Median relative-percent differences were determined for each analyte. Median values are reported because the median gives a better description of the bias than the mean. From January 1980 through September 1984 median relative-percent differences were positive for all six analytes. Median relative-percent differences were positive for all analytes except sulfate in the 1983 performance-audit samples; the median relative-percent difference was negative.

Estimated variances were determined for the six analytes reported by the NADP/NTN for January 1980 through September 1984, and for 1983, and can be used to estimate the precision of these data. Estimated pooled standard deviations and 95-percent confidence limits for the NADP/NTN reported analytes calcium, magnesium, sodium, potassium, sulfate, and chloride are reported for 1983.

All estimates of the variances and relative-percent differences for the six analytes (calcium, magnesium, sodium, potassium, sulfate, and chloride) reported by the NADP/NTN are based on performance-audit sample results. All performance-audit samples were submitted to CAL through NADP/NTN fieldsampling sites. These data are valid for the concentration ranges monitored by the performance-audit samples but may not be valid if these data are applied to natural-precipitation-sample concentrations beyond the concentration limits tested. 
Dixon, W.J., and Massey, F.J., 1969, Introduction to statistical analysis (3d ed.): New York, McGraw-Hil1, p. 72-83, 112-123.

Grant, E.L., and Leavenworth, R.S., 1974, Statistical quality control (4th ed.): New York, McGraw Hil1, p. 212-287.

Peart, D.B., and Thomas, Nancy, 1983, Quality-assurance data for routine water analysis in the laboratories of the U.S. Geological Survey, 1981 Annual Report: U.S. Geological Survey Water-Resources Investigations Report 83-4090, p. 4-7.

Schroder, L.J., Fishman, M.J., Friedman, L.C., and Darlington, G.W., 1980, The use of standard reference water samples by the U.S. Geological Survey: U.S. Geological Survey Open-File Report 80-738, 12 p.

Skougstad, M.W., and Fishman, M.J., 1974, Standard reference water samples, in Proceedings of the American Water Works Association, Water Quality Technology Conference, Dallas, Texas: p. XIX-1-60.

Walpole, R.E., and Myers, R.H., 1972, Probability and statistics for engineers and scientists (2d ed.): New York, Macmillan, p. 66-213, 282-300. 